1. Final Year MBBS, UCMD

2. Assistant Professor Community Medicine

Independent Medical College,

Faisalabad.

3. Final Year MBBS UCMD

Correspondence Address:

Naila Jabbar

Final Year MBBS UCMD

University of Lahore

dr.nailajabbar@gmail.com

Article received on:

28/02/2015

Accepted for publication:

08/08/2015

Received after proof reading: 09/09/2015

\section{TUBERCULOSIS MANAGEMENT; HOW WELL DO OUR MEDICAL PRACTITIONERS KNOW IN LAHORE HOSPITALS?}

\begin{abstract}
Naila Jabbar ${ }^{1}$, Dr. Muhammad Arif Ali $^{2}$, Umair Sohail ${ }^{3}$
ABSTRACT... Background: Medical practitioners are the main source of health care for patients in Pakistan due to their availability at all times. Limited information is available related to the management of Tuberculosis (TB) among the practitioners. Study Design: Cross sectional study. Setting: Through stratified random sampling among the practitioners of Lahore, Punjab. Period: May 2014 to August 2014. Methods: They were presented with a questionnaire and their answers examined according to the international designed strategy for TB management. Results: TB management has a positive relationship with experience, awareness, source of awareness and continuing medical education and a negative relationship with qualification. 95 $\%$ of doctors agreed to go for further investigation but only $40 \%$ knew that 2 sputum samples were required for proper diagnosis. Only 32\% doctors knew TB resistant drugs were to be given in drug resistant cases. Conclusion: Most doctors in Pakistan lack sufficient knowledge regarding tuberculosis management and prompt measures shall be taken to improve it.
\end{abstract}

Key words: $\quad$ CME: Continuing medical education; DOTS: Directly observed treatment short course, TB: Tuberculosis.

Article Citation: Jabbar N, Ali MA, Sohail U. Tuberculosis management; how well do our medical practitioners know in Lahore hospitals? Professional Med J 2015;22(9):1144-1149. DOI: 10.17957/TPMJ/15.2835

\section{INTRODUCTION}

Tuberculosis is a major public health problem in most developing countries of the world. ${ }^{1}$ Considered endemic throughout our country, Pakistan ranks $5^{\text {th }}$ amongst the 22 countries designated as severely affected by tuberculosis according to World Health Organization standard. ${ }^{2}$ The present annual incidence of TB cases is between $85-100 / 100,000$ persons and approximately an alarming 361,000 cases are added every year. ${ }^{3}$ It accounting for about 1.4 million deaths globally. ${ }^{4}$ Tuberculosis is an emerging threat to both Rural and urban populations of Pakistan; ${ }^{5}$ which alone accounts for $44 \%$ of the total TB burden of the Eastern world. Out of a population of 144 million, approximately 1.5 million people suffer from tuberculosis, exceeding $1 \%$ of the population. ${ }^{6}$ Pakistan also ranks as the $4^{\text {th }}$ highest prevalent multi-drug resistance TB country. ${ }^{7}$ Pakistan has a mixed type of health care system that includes both private and public centers. ${ }^{2}$ Since the introduction of DOTS (Directly Observed Therapy Short-course) in 1993 by WHO, conflicting re- sults have been showed by studies in Pakistan. ${ }^{8}$ Evidence suggests that private practitioners are not well equipped with the knowledge required for management of TB. ${ }^{9-13}$ Studies have showed that about $24 \%$ of the population does not have access to the DOTS program. ${ }^{6}$ Many researchers have been conducted worldwide both in high prevalence and low prevalence countries. ${ }^{14} \mathrm{~A}$ research by the Pune Municipal Corporation India concluded that only $11 \%$ of practitioners followed the 6 diagnostic standards of Tuberculosis in clinical setting. ${ }^{9}$ According to a further research in Croatia $87.9 \%$ of physicians required further knowledge about TB management. ${ }^{11} \mathrm{~A}$ research in Saudi Arabia also concluded that TB remains as the main problem due to a lack of knowledge amongst the public. ${ }^{9} \mathrm{~A}$ research conducted in Pakistan showed that due to lack of knowledge practitioners tend to adapt methods suitable to them for handling of situations. ${ }^{15}$ Similar researches had been conducted in two largely populated and well developed cities of Pakistan; Karachi and Islamabad, showing the same results. ${ }^{2,3,6}$ 


\section{PROBLEM STATEMENT}

According to $\mathrm{WHO}$ the involvement of health providers is an essential component of the "stop Tb strategy". ${ }^{10}$ Health care delay in diagnosis of this can increase the risk of its spread. ${ }^{16} \mathrm{~A}$ higher level of knowledge among physicians is important in order to achieve efficient case finding and management. ${ }^{11}$

\section{Rationale}

No such research has been conducted in Lahore, a city which harbors a large number of people. The aim of our study is to see the awareness of the DOTS program and TB management among practitioners in Lahore.

\section{Objectives}

To identify the gap in knowledge regarding diagnosis and management of TB in practitioners of Lahore, Pakistan. To see the extent of knowledge of medical practitioners exhibit related to TB management.

\section{Operational Definitions}

Dependent variable: Tb management- the way TB diseases are diagnosed, investigated, managed and treated. Independent variable: Awareness: know-how of the disease, Practitioner: who is practicing in the medical field?

\section{MATERIALS \& METHODS}

\section{Study design}

This was a cross sectional study of practitioners in Lahore, Punjab, Pakistan.

\section{Study setting}

Lahore the capital city of the province Punjab, Pakistan and the second large metropolitan city in the country. It ranks among 42 largest cities harboring about $9,600,000$ people. This city was selected purposefully because of the large and diverse target population, immense number of patients and large number of doctors practicing their medicine.

\section{Study duration}

This study was conducted over a period of 4 months from May 2014 to August 2014. Study population: The study population included doctors from different densely populated hospitals of Lahore. All doctors irrespective of their association with government or private institutes were included in the study.

\section{Sample selection}

\section{Inclusion criteria}

Doctors who practice medicine from different hospitals and manage TB related cases in their daily lives in Lahore.

\section{Exclusion criteria}

Surgeons, gynecologists, ophthalmologists, ENT specialists and dermatologists who do not deal with TB patients in their routine clinical settings.

\section{Sample size and sampling}

The sample was selected using stratified random allocation and 100 different practitioners from 5 of the most populated hospitals of Lahore were given the questionnaire. Prior notice was not given to the doctors and they were tested on the spot for their knowledge regarding TB management.

\section{Data variables}

Data collected included the general information about the practitioner, his or her working years in the field, information related to dots, primary tests for tuberculosis, prescription of the disease, duration of treatment, diagnosis of tuberculosis resistant cases and the related treatment.

\section{Data collection}

The questionnaire was taken from a research in India and was distributed amongst the study participants. This was done as the local settings of India and Pakistan are very similar. The questionnaire contained both vignettes and open ended questions. The key was designed according to the international standards given; if the response was according to the standard it was appointed grade 3 , grade 2 if the response was not appropriate and grade 1 if no response was shown. 
Groups of the surveyors were made which were then appointed different hospitals for completing the survey and collecting results under supervision.

\section{Data quality assurance}

In order to maintain accuracy of results, the questionnaires were solved under supervision of the surveyor and checked thoroughly before collection. The questionnaire was explained in detail before handling.

\begin{tabular}{|c|c|c|c|}
\hline & & & Adjuste \\
\hline Model & $\mathrm{R}$ & R Square & Adjusted R S \\
\hline 1 & $.503^{a}$ & .253 & .213 \\
\hline & & a. Predictors: ( & Constant), cm \\
\hline & & & b. Depender \\
\hline & & & Table-I. F \\
\hline & ple Kolm & yorov-Smirnov & Test \\
\hline & & & mean \\
\hline & $\mathrm{N}$ & & 100 \\
\hline Normal & atora b & Mean & 2.0708 \\
\hline INomal & , els & Std. Deviation & .23133 \\
\hline & & Absolute & .151 \\
\hline Most Extre & ferences & Positive & .130 \\
\hline & & Negative & -.151 \\
\hline & yorov-Smi & ov Z & 1.506 \\
\hline & Sig. (2-t & led) & .021 \\
\hline & e-II. Chec & for Normality & \\
\hline
\end{tabular}

The above table checks the normality of our dependent variables (TB management). Its significance value is .02 which means TB management normal at $5 \%$ and also converted in quantitative values. So we are safe to go with OLS regression for analysis of our sample data.
Data analysis

Data was analyzed through the SPSS V.17.0 software.OLS regression is used for analysis of the sample.

\section{RESULTS}

$R$ square is $21.3 \%$ which shows the variation in TB management. It means our used parameters for knowledge of practitioners are contributing $21.3 \%$ in TB management.

\begin{tabular}{|c|c|c|c|c|c|}
\hline \multicolumn{5}{|c|}{ ANOVA $^{\mathbf{b}}$} \\
\hline Model & Sum of Squares & df & Mean Square & F & Sig. \\
\hline Regression & 1.340 & 5 & .268 & 6.365 & $.000^{\text {a }}$ \\
\hline Residual & 3.958 & 94 & .042 & \\
\hline Total & 5.298 & 99 & \\
\hline \multicolumn{4}{r|}{ a. Predictors: (Constant), cme1, awareness, source, expe, qal1 } \\
\hline
\end{tabular}




\begin{tabular}{|c|c|c|c|c|c|c|c|c|}
\hline \multicolumn{9}{|c|}{ Coefficients $^{a}$} \\
\hline & & \multicolumn{2}{|c|}{$\begin{array}{l}\text { Unstandardized } \\
\text { Coefficients }\end{array}$} & \multirow{2}{*}{$\begin{array}{c}\text { Standardized } \\
\text { Coefficients } \\
\text { Beta }\end{array}$} & \multirow[b]{2}{*}{$\mathrm{t}$} & \multirow[b]{2}{*}{ Sig. } & \multicolumn{2}{|c|}{ Collinearity Statistics } \\
\hline & & B & Std. Error & & & & Tolerance & VIF \\
\hline \multirow{6}{*}{1} & (Constant) & 1.109 & .264 & & 4.206 & .000 & & \\
\hline & expe & .012 & .012 & .110 & 1.012 & .314 & .672 & 1.488 \\
\hline & awareness & .294 & .075 & .511 & 3.909 & .000 & .465 & 2.148 \\
\hline & source & .003 & .014 & .018 & .188 & .851 & .866 & 1.154 \\
\hline & qal1 & -.010 & .036 & -.034 & -.266 & .791 & .487 & 2.052 \\
\hline & cme1 & .098 & .056 & .170 & 1.727 & .087 & .825 & 1.212 \\
\hline \multicolumn{9}{|c|}{ a. Dependent Variable: mean } \\
\hline \multicolumn{9}{|c|}{ Table-IV. Coefficient Table } \\
\hline
\end{tabular}

\section{DISCUSSION}

Many researchers have been conducted in $\mathrm{Pa}$ kistan related to TB management. This is the first study conducted in Lahore Pakistan which harbors a large number of smear positive and smear negative patients. Previous surveys done in the country have showed tremendous lack of knowledge related to the management. ${ }^{17}$ Studies conducted in Peru, Oman and India showed presence of significant less information and practices related to the handling of these cases. ${ }^{18-20}$ Household contact screening of at risk individuals for TB is a relatively new concept in Pakistan and incorporated in NTP training of doctors since 2009. Findings of a systematic review and meta-analysis suggests that contact screening is an effective way to mend early case detection and decrease transmission especially in low and middle income high burden countries. ${ }^{21}$ In this study survey vignette and scenario type questions were used to assess the practitioners. Vignettes or written case simulations have been used widely to assess clinical knowledge and competence of a group of providers. ${ }^{22}$ Selected medical practitioners were chosen from 5 major hospitals including Jinnah hospital, Mayo hospital, Services hospital, Sheikh Zayed hospital and Ganga Ram hospital so our results can be generalized to the major population of house officers in Lahore. According to the results analyzed by the SPSS software, it was shown that $95 \%$ of doctors know how to proceed for investigations for diagnosis of TB but $60 \%$ of them failed to answer that 2 sputum samples are required for confirmatory diagnosis of TB. In question 5 and question 6 doctors were asked about the correct regimen and duration of treatment. $60 \%$ of the practitioners did not know the correct regimen and when asked.

About the duration of the treatment, $45 \%$ failed to answer correctly. In a scenario based question 9 a drug resistant case was presented to the doctors. Despite the pervasiveness of TB drug resistant cases in our society $68 \%$ failed to prescribe TB resistant drug thus showing a lack of information and knowledge about TB resistant cases in our setup.

\section{Limitations of the study}

In this study only selected practitioners from different hospitals were included and were allowed to solve the questionnaire. They may not represent the presenting population. Also, the sample size was small compared to the number of doctors practicing medicine in Lahore.

\section{CONCLUSION}

Our study found that international standards of tuberculosis management are not commonly followed by the doctors in Lahore, Pakistan. As Pakistan plans to eradicate and lower the burden of TB in the country, the program needs to beprioritized.

\section{Recommendations}

1- Basic education related to TB management must be included in detail during MBBS course. 
2- Trials of management must be given to the beginners.

3- Detailed seminars related to the TB management must be organized on regular basis.

4- Doctors and students must be encouraged to actively participate in the activity.

5- Screening programs must be launched to detect subclinical cases.

\section{Acknowledgments}

We are thankful to Dr. Raja for his guidance throughout the study and explaining the details research methodology. The group also thanks the department of Community Medicine at University of Lahore and Head of Dept. Dr. Abdul Rasheed for providing us with the opportunity to take this topic and research on it. We pay our gratitude to all those who help us in collecting data.

Copyright@ 08 Aug, 2015.

\section{REFERENCES}

1. Organization WH. World Health Organization Global Tuberculosis Report 2013. World Health Organization, WHO Press, Geneva, Switzerland. 2013.

2. Naseer M, Khawaja A, Pethani AS, Aleem S. How well can physicians manage Tuberculosis? A Public-Private sector comparison from Karachi, Pakistan. BMC health services research. 2013;13(1):439.

3. Hussain A, Mirza Z, Qureshi FA, Hafeez A. Adherence of private practitioners with the National Tuberculosis Treatment Guidelines in Pakistan: a survey report. J Pak Med Assoc. 2005;55(1):17-9.

4. Arshad A, Salam RA, Lassi ZS, Das JK, Naqvi I, Bhutta $Z A$. Community based interventions for the prevention and control of tuberculosis. Infectious diseases of poverty. 2014;3(1):27.

5. Ahmed M, Fatmi Z, Ali S, Ahmed J, Ara N. Knowledge, attitude and practice of private practitioners regarding TB-DOTS in a rural district of Sindh, Pakistan. J Ayub Med Coll Abbottabad. 2009;21(1):28- 31.

6. Khan J, Akbani F, Malik A, Kazi G, Aslam F. Effect of providing free sputum microscopy service to private practitioners on case notification to National Tuberculosis Control Program. Journal of Ayub Medical College Abbottabad. 2015;17(4):5.

7. Yasmin M, Gomgnimbou MK, Siddiqui RT, Refrégier G, Sola C. Multi-drug resistant Mycobacterium tuberculosis complex genetic diversity and clues on recent transmission in Punjab, Pakistan. Infection, Genetics and Evolution. 2014;27:6-14.

8. Pope $D$, Chaisson R. TB treatment: as simple as DOT?[Counterpoint]. The International Journal of Tuberculosis and Lung Disease. 2003;7(7):611-5.

9. Bharaswadkar S, Kanchar A, Thakur N, Shah S, Patnaik $B$, Click ES, et al. Tuberculosis Management Practices of Private Practitioners in Pune Municipal Corporation, India. PloS one. 2014;9(6):e97993.

10. Yimer SA, Holm-Hansen C, Bjune G. Assessment of knowledge and practice of private practitioners regarding tuberculosis control in Ethiopia. The Journal of Infection in Developing Countries. 2011;6(01):13-9.

11. Jurčev Savičević A. Gaps in tuberculosis knowledge among primary health care physicians in Croatia: epidemiological study. Collegium antropologicum. 2009;33(2):481-6.

12. Datta K, Bhatnagar T, Murhekar M. Private practitioners' knowledge, attitude and practices about tuberculosis, Hooghly district, India. Indian J Tuberc. 2010;57(4):199-206.

13. Abouzeid MS, Zumla Al, Felemban S, Alotaibi B, O'Grady J, Memish ZA. Tuberculosis trends in Saudis and non-Saudis in the Kingdom of Saudi Arabia--a 10 year retrospective study (2000-2009). PloS one. 2012;7(6):e39478.

14. Akachi $Y$, Zumla A, Atun R. Investing in improved performance of national tuberculosis programs reduces the tuberculosis burden: analysis of 22 high-burden countries, 2002-2009. Journal of Infectious Diseases. 2012;205(suppl 2):S284-S92.

15. Malik AU, Willis CD, Hamid S, Ulikpan A, Hill PS. Advancing the application of systems thinking in health: advice seeking behavior among primary health care physicians in Pakistan. Health Res Policy Syst. 2014;12(43):10.1186.

16. Chen T-C, Lu P-L, Lin W-R, Lin C-Y, Lin S-H, Lin C-J, et al. Diagnosis and treatment of pulmonary tuberculosis in hospitalized patients are affected by physician specialty and experience. The American journal of the medical sciences. 2010;340(5):367-72.

17. Shah S, Sadiq H, Khalil M, Noor A, Rasheed G, Shah S, et al. Do private doctors follow national guidelines for managing pulmonary tuberculosis in Pakistan? 2003.

18. Chiang SS, Cruz AT, Del Castillo H, Contreras C, Becerra MC, Lecca L. Evaluation of health-care providers' knowledge of childhood tuberculosis in Lima, Peru. Paediatrics and international child health. 2015;35(1):29- 
35.

19. Srivastava D, Mishra A, Mishra S, Chouksey M, Jain P, Gour N, et al. A comparative assessment of KAP regarding tuberculosis and RNTCP among government and private practitioners in District Gwalior, India: an operational research. The Indian journal of tuberculosis. 2011;58(4):168-77.

20. Al-Maniri AA, Al-Rawas OA, Al-Ajmi F, De Costa A, Eriksson $B$, Diwan VK. Tuberculosis suspicion and knowledge among private and public general practitioners: Questionnaire Based Study in Oman. BMC Public Health. 2008;8(1):177.

21. De Muynck A, Siddiqi S, Ghaffar A, Sadiq H. Tuberculosis control in Pakistan: critical analysis of its implementation. J Pak Med Assoc. 2001;51(1):41-7.

22. Miller GE. The assessment of clinical skills/competence/performance. Academic medicine. 1990; 65(9):S63-7.

\section{PREVIOUS RELATED STUDY}

Aftab Anjum, Seema Daud, Fatima Mukhtar. TUBERCULOSIS (Original) Prof Med Jour 16(1) 61-66 Jan, Feb, Mar 2009.

Abdul Salam Malik, Gulzar Ahmad. TUBERCULOSIS (Original) Prof Med Jour 16(1) 70-77 Jan, Feb, Mar 2009.

Javed Iqbal, Altaf Hussain Malik, Khalil Ahmed Shahid. PREVALENCE OF TUBERCULOSIS IN JAIL (Original) Prof Med Jour 18(3) 462-465 Jul, Aug, Sep 2011.

Javed Iqbal, Altaf Hussain Malik, Aftab Jamil. Latent tuberculosis; jail as a risk factor. (Original) Professional Med J Jan-Feb 2012;19(1): 059-062.

\section{"If people are trying to bring you down, It only means that you are above them."}

\section{Unknown}

\section{AUTHORSHIP AND CONTRIBUTION DECLARATION}

\begin{tabular}{|c|l|l|l|}
\hline Sr. \# & \multicolumn{1}{|c|}{ Author-s Full Name } & \multicolumn{1}{|c|}{ Contribution to the paper } & Author=s Signature \\
\hline 1 & Naila Jabbar & $\begin{array}{l}\text { Its a collaborated effort by } \\
\text { authors }\end{array}$ \\
\hline 3 & Dr. Muhammad Arif Ali & Umair Sohail & \\
\hline
\end{tabular}

